\section{Extracavally Malpositioned Central Venous Catheter}

Sir,

Central venous catheterisation is used for many indications in intensive care units. ${ }^{1,2}$ Due to anatomical and pressure changes in the thorax, malpositioning may occur during or after catheter placement, especially in trauma patients. ${ }^{2}$ Herein, we describe a case of extracavally malpositioned subclavian catheter that has not been reported previously to the best of our knowledge.

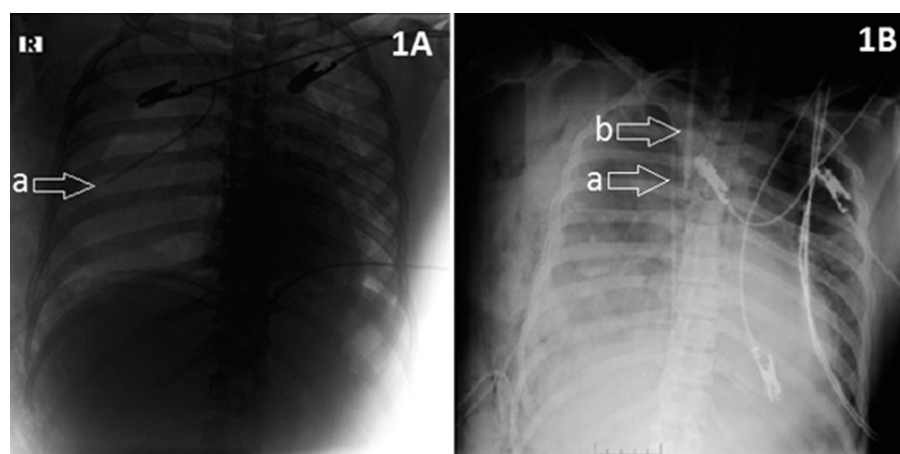

Figure 1A: CVC malposition (a) in the chest X-ray. 1B: Malpositioned CVC (a) and newly placed IJC (b) in the chestX-ray.

CVC: Central venous catheter, IJC: Internal jugular catheter.

A right subclavian catheterisation was accomplished at a primary centre in a 44-year woman who was admitted because of a suicidal attempt. The patient had fallen from a height of 10 metres and had complex pelvic fractures, multiple thoracic vertebral and rib fractures as well as a right hemopneumothorax. As the hemoglobin $(\mathrm{Hb})$ was $7.1 \mathrm{~g} / \mathrm{dL}$, three units of erythrocyte suspension and two units of fresh frozen plasma were transfused. After tube thoracostomy, the patient was referred to this centre. The patient was conscious but anxious on arrival. She had a Glasgow coma scale (GCS) of 15 and was admitted to Anesthesiology Intensive Care Unit. Blood pressure was $84 / 50 \mathrm{mmHg}$, respiratory rate was $20 / \mathrm{min}$, heart rate $102 / \mathrm{min}$. and repeat $\mathrm{Hb}$ was $5.7 \mathrm{~g} / \mathrm{dL}$ and there was 400 $\mathrm{mL}$ of bloody content in the right thorax tube drainage. This low $\mathrm{Hb}$ and lack of adequate hemodynamic stability in spite of transfusion as well as high volume of bloody content in the chest tube reminded us of a central venous catheter (CVC) malpositioning. The malpositioning was confirmed by chest X-ray (Figure 1). In computed tomography (CT) of thorax, there was pleural fluid in both hemithoraces. A $5.5 \mathrm{~cm}$ thick pneumothorax with accompanying right pleural fluid and an almost fully collapsed right lung were radiologically detected. CVC was extending into right hemithorax from right subclavicular area and was not associated with any vascularstructure. The catheter wasadjacent to the superior right wall of the vena cava inferiorly and the tip was at the right hilarregion, in the vicinity of pulmonaryartery and superiorpulmonary vein (Figure 2). As the patient required a proper CVC, right internal jugular vein catheterisation was performed under ultrasonographic guidance after withdrawal of the malpositioned catheter (Figure 1B).

In a properly placed CVC, the tip of the catheter should be at the junction of superior vena cava and the right atrium. On chest Xray, this is exactly $2 \mathrm{~cm}$ proximal to the pericardial line. The two most common complications following subclavian vein catheterisation are pneumothorax and malposition. After insertion of CVC, both complications can be determined by routine chest radiography. ${ }^{3}$ In our patient, $\mathrm{Hb}$ was not increasing despite transfusion. In addition, the presence of large volume of bloody fluid in chest tube drainage and the failure to achieve hemodynamic stability suggested the possibility of catheter malposition.
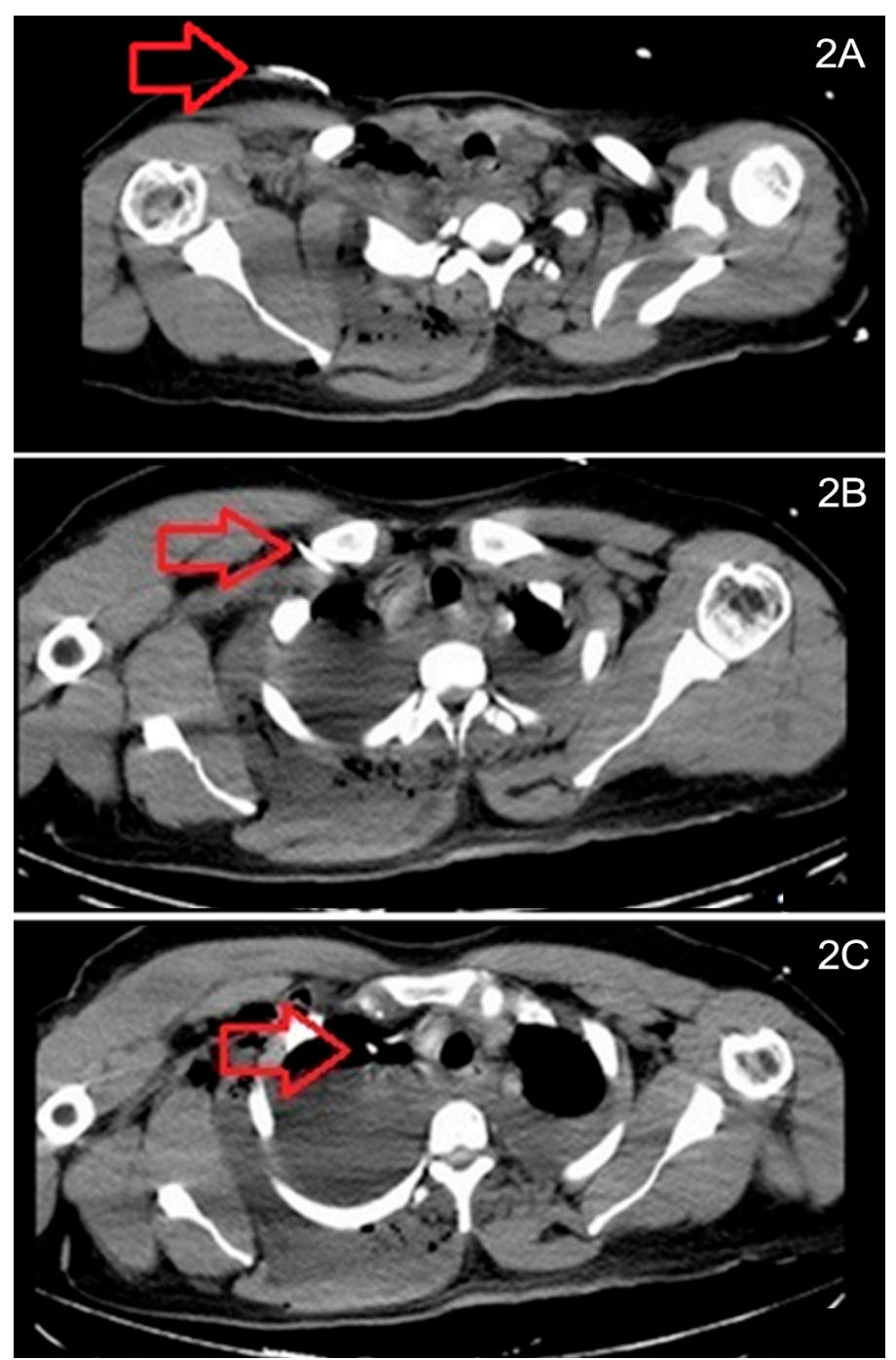

Figure $2(A, B, C)$ : CVC extending into thorax from right subclavicular area and not associated with vascular structure, following inferiorly adjacent to the superior right wall of the vena cava and ending at the right hilar region (in the vicinity of pulmonary artery and superior pulmonary vein.

Malposition can be of two types, namely intracaval and extracaval, on the basis of the catheter site. In extracaval malposition, the catheter may be located at mediastinum, pleura, trachea, esophagus and subarachnoid space. Catheter malposition is often associated with serious consequences resulting in misdiagnosis and delayed treatment. ${ }^{4}$ In this patient, the physician who malpositioned the catheter at the primary centre might have been inexperienced and might not have the opportunity or knowledge to perform the procedure under ultrasonographic guidance. In addition, initiation of fluid treatment without radiological confirmation of the location of the catheter tip caused treatment failure. Considering the transport time of the patient and the time elapsed 
for diagnosing the malpositioned catheter, patient's blood product replacement had failed to increase $\mathrm{Hb}$ levels and the achievement of hemodynamic stability was delayed.

In conclusion, it is imperative to confirm radiologically that the CVC tip is at the right intravascular position before massive fluid resuscitation, especially in patients with large hemopneumothorax. In this way, hemodynamics of the patient can be stabilised and complications due to malposition of CVC can be prevented soon after catheterisation.

\section{CONFLICT OF INTEREST:}

Authors declared no conflict of interest.

\section{AUTHORS' CONTRIBUTION}

GA: Writer, design, materials, literature review.

ZA: Supervision, critical review.

\section{REFERENCES}

1. Takhar PR, Motilal B, Savita A. Malpositioning of central venous catheter from right to left subclavian vein a rare complication. Indian J Crit Care Med 2017; 21: 799-801.

2. Ghatak T, Azim A, Baronia AK, Muzaffar SN. Malposition of central venous catheter in a small tributary of left brachiocephalic vein. J Emerg Trauma Shock 2011; 4:523-5.

3. Brown JR1, Slomski C, Saxe AW. Is routine post-operative chest $\mathrm{x}$-ray necessary after fluoroscopic-guided subclavian central venous port placement. J Am Coll Surg 2009; 208: 517-9.

4. Kela M, Munde H, Raut S. Accidental placement of central venous catheter into internal mammary vein a rare catheter malposition. Ann Card Anaesth 2017; 20:477-8.

Gülçin Aydın and Zeynepnur Akçaboy

Department of Anesthesiology and Reanimation, School of Medicine, Kirikkale University, Kirikkale, Turkey

Correspondence to: Dr. Gülçin Aydın, Department of Anesthesiology and Reanimation, School of Medicine, Kirikkale University, 71450, Yahsihan, Kirikkale, Turkey

E-mail:drgulcinaydin@yahoo.com

Received: April 12, 2019; Revised: July 17, 2019; Accepted: July 22, 2019

DOI: https://doi.org/10.29271/jcpsp.2020.04.459 